\title{
Performance of microAethalometers: Real-world Field Intercomparisons from Multiple Mobile Measurement Campaigns in Different Atmospheric Environments
}

\author{
Honey Dawn C. Alas ${ }^{1 *}$, Thomas Müller ${ }^{1}$, Kay Weinhold ${ }^{1}$, Sascha Pfeifer ${ }^{1}$, Kristina Glojek ${ }^{2}$, \\ Asta Gregorič ${ }^{3,4}$, Griša Močnik ${ }^{3,5}$, Luka Drinovec ${ }^{3,5}$, Francesca Costabile ${ }^{6}$, Martina Ristorini ${ }^{7}$, \\ Alfred Wiedensohler ${ }^{1}$
}

${ }^{1}$ Leibniz Institute for Tropospheric Research, Leipzig, Germany

${ }^{2}$ Department of Geography, Faculty of Arts, University of Ljubljana, Ljubljana, Slovenia

${ }^{3}$ Center for Atmospheric Research, University of Nova Gorica, Ajdovščina, Slovenia

${ }^{4}$ Aerosol d.o.o., Kamniška 39 A, 1000 Ljubljana, Slovenia

${ }^{5}$ Condensed Matter Physics Department, J. Stefan Institute, Ljubljana, Slovenia

${ }^{6}$ Institute of Atmospheric Science and Climate, National Research Council, Rome, Italy

${ }^{7}$ Department of Bioscience and Territory, University of Molise, Pesche, Italy

\begin{abstract}
Small aethalometers are frequently used to measure equivalent black carbon (eBC) mass concentrations in the context of personal exposure and air pollution mapping through mobile measurements (MM). The most widely used is the microAethalometer (AE51). Its performance in the laboratory and field is well documented, however, there is not sufficient data in the context of its performance in different environments. In this investigation, we present the characterization of the performance of the AE51 through field unit-to-unit intercomparisons (IC), and against a reference absorption photometer from three MM campaigns conducted in drastically different environments. Five IC parameters were considered: i) study area, ii) location of IC, iii) time of day, iv) duration of IC, and v) correction for the filter-loading effect. We can conclude that it is crucial where and how long the IC have been performed in terms of the correlation between the mobile and reference instruments. Better correlations $\left(\mathrm{R}^{2}>0.8\right.$, slope $\left.=0.8\right)$ are achieved for IC performed in rural, and background areas for more than 10 minutes. In locations with more homogenous atmosphere, the correction of the loading effect improved the correlation between the mobile and reference instruments. In addition, a newer microAethalometer model (MA200) was characterized in the field under extreme cold conditions and correlated against another MA200 $\left(\mathrm{R}^{2}>0.8\right.$, slope $\left.\approx 1.0\right)$, AE51 $\left(\mathrm{R}^{2}>0.9\right.$, slope $\left.\approx 0.9\right)$, and a stationary Aethalometer (AE33) across all wavelengths $\left(\mathrm{R}^{2}>0.8\right.$, slope $\left.\approx 0.7\right)$. For MA200, the loading effect was more pronounced, especially at the lower wavelengths, hence the correction of the loading effect is essential to improve the correlation against the AE33. The MA200 and AE51 proved to be robust and dependable portable instruments for MM applications. Real-world quality assurance of these instruments should be performed through field IC against reference instruments with longer durations in areas of slowly changing eBC concentration.
\end{abstract}

Keywords: Portable instruments; Mobile monitoring; Black carbon; Instrument intercomparisons.

\section{INTRODUCTION}

Black carbon (BC) particles are an increasingly important air pollutant in terms of human exposure to combustionrelated emission sources such as traffic and wood burning. Since these particles are highly variable in space (Peters et

\footnotetext{
* Corresponding author.

Tel.: +49 341 2717-7372; Fax: + 493412717997060

E-mail address: alas@tropos.de
}

al., 2014a; Rakowska et al., 2014) due to their size (20$300 \mathrm{~nm}$ ), their spatial distribution should be determined with high resolution to estimate different exposure scenarios. This has become possible with the rise of portable instrumentation with fast measurements placed in mobile platforms.

The microAethalometer (microAeth ${ }^{\circledR}$ AE51 model, Aethlabs, San Francisco, CA) is currently the most widely used portable absorption photometer for measurements of BC mass concentrations aboard mobile platforms. The AE51 measures the attenuation of light $(880 \mathrm{~nm})$ through a particle-loaded filter (T60 Teflon coated glass fiber) and converts this to an equivalent black carbon (eBC; Petzold $e t$ 
al., 2013) mass concentration using a fixed mass attenuation coefficient (MAC). The time resolution can be set from 300 seconds down to 1 second. It is also small enough to fit in a pocket, making it extremely portable. This instrument is the most characterized portable instrument for eBC measurements in terms of filter loading effect (Cheng and Lin, 2013; Good et al., 2017), and sensitivity to sudden changes in relative humidity, temperature (Cai et al., 2013), and vibration (Apte et al., 2011). To investigate the performance of any instrument, it is often compared against "reference" instruments with operating principles considered as standard method. While there is no standard method to measure BC, there are three potential candidate methods to measure aerosol absorption abinitio. These methods are capable of measuring the absorption of particles suspended in the air, rather than collected on a filter. The first method measures extinction and scattering, and calculates the absorption as the difference between them. This method works for single-scattering albedo values below about 0.8 . The second is the photoacoustic method which measures the pressure waves generated by modulated absorption of light by aerosols, subsequent heating and change in the density of the air. Usually, a resonant cavity is employed to amplify the signal. This resonance needs to be tracked and is sensitive to changes in ambient conditions. The signal is also dependent on the losses to latent heat as the coating of the particles changes phase. The third is the photothermal interferometry which employs a similar heating of the sample, measuring the change in the refractive index following the change in density. All methods require drying of the sample. Filter photometers are commonly used in the field. Light from an LED source passes through a particleloaded filter, and is detected by a photodiode. The amount of light attenuated by the light-absorbing particles trapped in the filter is proportional to the concentration of these particles. The light absorption coefficient of the particles is converted to mass concentration of light absorbing carbon by dividing it with the MAC. The calculation assumes the filter properties in the derivation of the absorption coefficient introducing uncertainties into the reported parameters. This method provides "mass equivalent black carbon" or "eBC" as recommended by Petzold et al. (2013). However, MAC can vary widely as a function of particles' physical (i.e., coating) and chemical (composition) properties across different locations and atmospheric conditions. Consequently, this is a source of uncertainty for optically derived mass concentrations of eBC. Despite this, light absorption instruments have been used in regular air quality monitoring in fixed locations across the globe due to its ease of use, online measurements, and high time resolution. In previous studies, the AE51 have been compared against rack-mounted versions of absorption photometers as they have the same operating principle and feature high time resolution. For instance, Viana et al. (2015) performed experiments on the unit-to-unit variability of the AE51 as well as intercomparisons (IC) against a reference instrument (multiangle absorption photometer or MAAP model 5012, Thermo, Inc., Waltham, MA USA) in a single location. However, this investigation was not done in the context of mobile measurements (MM). Birmili et al. (2013) and Alas et al. (2019) among others, have emphasized the importance of doing field IC between mobile devices and reference instruments during a mobile measurement round to ensure the quality of the data obtained. This way, the eBC mass concentrations obtained from the AE51 is harmonized with a more stable and quality-assured instrument. This has been done in practice by previous studies, but rarely focused on. The question remains: how does the AE51 compare against a reference absorption photometer in the context of MM performed over different environments and what factors influence their correlation?

The aim of this investigation is to determine the intercomparability of the AE51 against each other and against reference instruments using the data from three mobile field studies performed in multiple locations with varying sources and atmospheric conditions. These measurement campaigns used the same mobile platform, and followed the same experimental set up. All the mobile measurement routes included fixed stations that has absorption photometers serving as reference instrument for $\mathrm{eBC}$ mass concentrations for field IC of varying duration.

In addition, the field performance of relatively new, portable, 5-wavelength absorption photometers with PTFE filter material (microAeth ${ }^{\circledR}$ Model MA200, Aethlabs, San Francisco, CA) was investigated in comparison to its predecessor (AE51) and to a rack-mounted 7-wavelength aethalometer (Model AE33, Magee Scientific, Berkeley, CA, USA). This study focuses on the unit-to-unit variability of MA200, its intercomparison with the AE51, and the reference instrument, AE33. Sensitivity of this instrument to different factors such as temperature, pressure, humidity, etc. will not be analyzed as these have been published elsewhere (Düsing et al., 2019)

\section{METHODS}

\section{Locations}

This section briefly describes the instrumentation used as well as the mobile measurement experiments performed in the following campaigns:

i Metro Manila Aerosol Characterization Experiment (MACE-2015, “Manila campaign”), Philippines

ii Carbonaceous Aerosol in Rome and Environs (CARE2017, "Rome campaign), Italy

iii Loški Potok, Slovenia (LP-2018, “Loški Potok campaign”).

\section{Mobile Measurements (MM)}

The MM carried out for all three campaigns were more or less similar and descriptions can be found in the references listed in the footnotes of Table 1. Briefly, the AE51 is placed inside a hard-case, water-proof, backpack. The aerosol enters the system through a 1-m stainless steel inlet. The aerosol sample then passes through a silica-gel drier, which dries the aerosol and dampens the effects of sudden changes in humidity, before entering the AE51. A microcomputer logs the data and synchronizes it with the location information obtained by the GPS unit. The AE51 was operated with a flow of $100 \mathrm{~mL} \mathrm{~min}^{-1}$ and time stamp of 1 -s. However, to minimize noise and still have high resolution data, the 10 -second median of the eBC mass concentrations were obtained from 


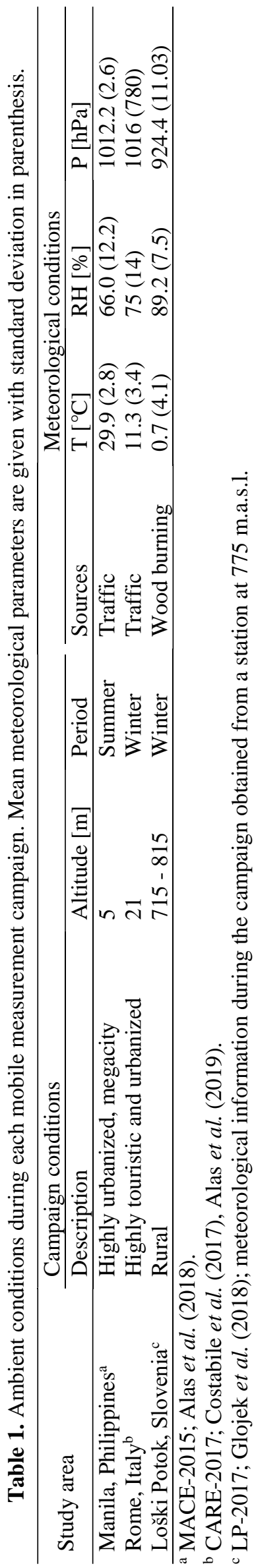

the 1-s data. For the case of the Loški Potok campaign, the MA200 was additionally installed downstream of the silica gel dryer and the flow rate was set to $150 \mathrm{~mL} \mathrm{~min}$.

The MM were done along fixed routes, which covered different microenvironments. Measurements were repeated along the routes to obtain representative information. All routes passed by a fixed station which contained the reference absorption photometer where the "runners", who carry the backpack, can stop for some time to intercompare the AE51 and MA200 (in the case of Loški Potok campaign) with the reference instruments (not on the same inlet, but in the same vicinity).

The different transit times of the aerosol being sampled through the inlets of the backpack and the container could influence the correlation between the two, especially in IC locations with rapidly fluctuating $\mathrm{eBC}$ concentrations. This was addressed by synchronizing the data loggers with internet time and aggregating the dataset. The 10 -s median from the mobile devices were further aggregated to 1-minute to be comparable to the reference instruments. This smooths out the possible lag in the measurements.

\section{Field Campaigns}

Table 1 describes the different campaigns and their mean ambient conditions. Table 2, on the other hand, summarizes the IC parameters for each campaign. For summary of the description of each instrument used in this study, including operating principles and technical specifications, see Table S1. The number of IC periods done per site is listed in Table S2.

\section{Manila, Philippines}

MACE-2015 was performed in the highly urbanized metropolitan (> 10M inhabitants) of Metro Manila, Philippines (tropical) in the summer time (March to June). During these months, the weather in Manila is typically warm (around $30^{\circ} \mathrm{C}$ ) with minimal rain and cloud cover. Winds are generally blowing from the East and gradually switches to Southwest at the onset of the monsoon season (middle of May). Here, the main source of eBC particles is traffic due to the lenient regulation of vehicular emissions and high volume of vehicles. For more information on MACE-2015, the readers are directed to the following publications (Kecorius et al., 2017; Alas et al., 2018; Kecorius et al., 2018; Kecorius et al., 2019; Madueño et al., 2019). Reference instruments were set-up permanently (for the duration of the experiment) inside a building within an urban background area (university campus). Simultaneously, an aerosol measurement container was placed $300 \mathrm{~m}$ away on a street side (phase 1) along Katipunan Avenue for more than a month. Then, the aerosol container was moved closer to the urban background station for a week of IC (phase 2). Finally, it was moved until the end of the campaign $20 \mathrm{~km}$ away to a street side along Taft Avenue (phase 3), which has street canyon configuration. The aerosol container and urban background station measured eBC mass concentrations with a MAAP. Two mobile measurement experiments were performed, one during phases 1 and 2, (including the urban background station) and one during phase 3. For both mobile measurement experiments, the IC 
Table 2. Intercomparison parameters for each campaign.

\begin{tabular}{|c|c|c|c|c|c|}
\hline \multirow{2}{*}{ Study area and routes } & \multicolumn{2}{|c|}{ Instruments } & \multicolumn{3}{|c|}{ Intercomparison parameters } \\
\hline & Mobile & Reference & Location & Time $^{\mathrm{a}}$ & Duration (min) \\
\hline \multicolumn{6}{|l|}{ Manila, Philippines } \\
\hline Katipunan Route & AE51 & MAAP & Urban street & $\mathrm{nn} \& \mathrm{pm}$ & $<5$ \\
\hline & & MAAP & Urban background & & \\
\hline Taft Route & AE51 & MAAP & Urban street canyon & $\mathrm{nn} \& \mathrm{pm}$ & $<5$ \\
\hline \multicolumn{6}{|l|}{ Rome, Italy } \\
\hline Rome city route & AE51 (2x) & MAAP & Urban background & $\mathrm{am}, \mathrm{nn}, \& \mathrm{pm}$ & 30 \\
\hline \multicolumn{6}{|l|}{ Loški Potok, Slovenia } \\
\hline Village route & AE51 (2x) & AE33 & Rural village & $\mathrm{am}, \mathrm{nn}, \& \mathrm{pm}$ & 20 \\
\hline & MA200 (2x) & $\mathrm{AE} 33$ & Rural background & & 10 \\
\hline
\end{tabular}

a "am" - morning; "nn" - noon to afternoon; "pm" - evening.

periods between the AE51 and the MAAP were shorter than 5 minutes.

IC was performed by placing the aerosol backpack(s) near the measurement container where the reference instruments are. For the urban street site, the aerosol container was $\sim 2 \mathrm{~m}$ away from the backpacks and with $\sim 3 \mathrm{~m}$ height difference between their inlets. For IC at the urban background site, there were two instances: IC against the reference instruments on the 4th floor of a building (as mentioned above), and IC against the aerosol container when it was moved near the same building for a week. The inlet of the of building site was $\sim 55 \mathrm{~m}$ from the inlets of the backpacks during IC periods. IC periods at the urban street and urban background were done within one run. Alas et al. (2018) have demonstrated that the difference in concentration between the building site and the aerosol container when they were in the same location was not significant. The mean eBC mass concentrations (standard deviation) at the building site was 6.9 (4.8) $\mathrm{\mu g} \mathrm{m}^{-3}$, while at the ground site with the aerosol container was 7.6 (4.9) $\mu \mathrm{g} \mathrm{m}^{-3}$ showing that particles in this location, specifically eBC particles, were spatially homogenous.

For the IC performed at the urban street canyon site, the same aerosol container was used but was mounted on 1-m cement blocks. Therefore, the vertical distance between the inlets of the aerosol container and the backpacks were $\sim 4 \mathrm{~m}$. The horizontal distance, on the other hand, is approximately $2 \mathrm{~m}$.

\section{Rome, Italy}

CARE-2017 was performed in the city of Rome, Italy, which is home to more than 3 million people. The campaign was done in February 2017 with temperatures ranging from 7 to $15^{\circ} \mathrm{C}$. Minimal rain events occurred during this time. The main sources of eBC particles were vehicular emissions and domestic heating. For this campaign, an aerosol container was placed inside a gated garden, which is considered an urban background area (Costabile et al., 2017). Collocated MM with two aerosol backpacks with identical instrumentation were performed around this station with a 30-minute IC duration (Alas et al., 2019). During this IC periods against the reference instruments, the backpacks were placed $\sim 3 \mathrm{~m}$ from the aerosol container inlets horizontally, and $\sim 4 \mathrm{~m}$ vertically. The IC period was performed 30 -minutes into the 2.5 hour run.

\section{Loški Potok, Slovenia}

The measurement campaign was performed in the model region Retje, Loški Potok, Slovenia, a populated, forested karst hollow with frequent ground temperature inversions and residential wood combustion as the main energy source. MM were performed from December 2017 to January 2018 with temperatures ranging from $-17.7^{\circ} \mathrm{C}$ to $14.2^{\circ} \mathrm{C}$ in the hollow. Two stations with reference instruments were set up in the studied area (Glojek et al., 2018), one at the bottom of the hollow in the Retje village (715 $\mathrm{m}$ a.s.l., rural village) and one on top of Tabor hill (815 $\mathrm{m}$ a.s.1., rural background site). At both stations, eBC mass concentrations were retrieved with AE33. Along the hollow, simultaneous MM were performed with a 20 -minute IC at the station in the village and with a 10-minute IC on top of the hill. The following instruments were intercompared: the AE51 and the MA200 with the AE33. IC at both stations were performed within one run (one filter). For the IC at the rural village, the backpacks' inlets were $\sim 8 \mathrm{~m}$ horizontally and $\sim 2 \mathrm{~m}$ vertically away from the inlets of the fixed station. For the IC at the rural background, the horizontal distance between the inlets was $\sim 2.5 \mathrm{~m}$ and the vertical distance was $\sim 3 \mathrm{~m}$.

\section{Data Processing}

The loading effect in filter photometers is a bias, which reduces the apparent concentrations relative to the ambient ones. The apparent reduction depends on the loading of the spot. The filter-loading effect (FLE) is a non-linearity due to the saturation of the attenuation (ATN) as the amount of the sample on the filter in the photometer continually increases - the eBC mass should depend only on the change of attenuation in time, but due to saturation, an ATN dependence is observed (Park et al., 2010; Segura et al., 2014; Drinovec et al., 2015). The FLE on eBC mass concentrations measured by filter-based photometers have been studied extensively. The two most direct way to detect this in post-processing is to plot the raw eBC mass concentrations as a function of the attenuation (ATN), and to compare against a reference instrument. The FLE depends on the type of particles sampled. Another method is the one outlined in Good et al. (2017), where an experimental set-up in the laboratory including a photoacoustic extinctionmeter (PAX) was used as a reference instrument, which, being not filter-based, is not susceptible to FLE. However, as this instrument was not used in any of 
the campaigns in this study, the $\mathrm{eBC}$ mass concentrations measured by the AE51 and MA200 were instead compared against the AE33 which has a real-time FLE correction, and the MAAP which, compared to the AE51, is less susceptible to the FLE (Petzold et al., 2005).

For the Manila and Rome datasets, three approaches to assess the FLE were performed:

1. BC(ATN) approach: Assessment of FLE on the whole dataset (measurements from the entire routes) by plotting the eBC concentrations as a function of the increasing ATN.

2. Deviation (ATN) approach: Assessment of FLE during the intercomparison periods (based on Masey et al. (2020)) analyzing the ratio and difference of eBC measurements between AE51 and reference instrument as a function of increasing AE51 ATN.

3. Virkkula correction approach: Assessment of FLE by correcting entire datasets using the Virkkula algorithm (Virkkula et al., 2007) with a loading parameter " $\mathrm{k}$ " from literature.

For BC(ATN) approach, the entire mobile measurement was used to assess the FLE. Raw, 1-s data from the AE51 was analyzed by plotting it against the ATN. To determine if FLE is present, the eBC measurements were binned in intervals of 1 ATN. A linear fit was performed for both the mean and median eBC measurements per ATN bin over the whole ATN range. Another experiment was to fit the mean and median values over only a specific ATN range. In Drinovec et al. (2015), they did not include the lowest and largest ATN values in the fitting due to low frequency of eBC measurements at those values. In this study, we did this by doing the BC(ATN) plots only for eBC values below the $95^{\text {th }}$ percentile of ATN. If the fit has a negative slope, the $\mathrm{eBC}$ is decreasing with increasing ATN, hence, there is a loading effect. Normally, the loading parameter to correct the AE51 raw concentrations can be derived from the slope and intercept of the regression line.

The deviation (ATN) approach follows that of Masey et al. (2020) to assess FLE during IC periods. The raw eBC mass concentrations measured by the AE51 during the IC periods were taken and aggregated to 1-min averages. Two statistical parameters were used to investigate deviation of the measurements between the AE51 and reference instruments as a function of the ATN of the AE51: the ratio (AE51/reference) and the difference (AE51 - reference). Similar to the first approach, the slope of the linear fit indicates the FLE.

The Virkkula correction approach was performed to investigate if correcting for the FLE significantly improves the AE51 measurements. The FLE correction algorithm by Virkkula et al. (2007) was used to correct the dataset. The loading parameter $(\mathrm{k}=0.005)$ applied here was taken from Drinovec et al. (2017) which is supposed to represent a diesel dominated aerosol type. In most of the studies involving AE51 measurements, the algorithm presented by Virkkula et al., 2007 is used as it is very simple (Cheng and Lin, 2013; Dons et al., 2013; Peters et al., 2014; Van den Bossche et al., 2015; Van den Bossche et al., 2016). Hence, it was also used in this study.
For the Loški Potok campaign, a different $\mathrm{k}$ has to be derived for the MA200 as it uses a different filter material from the AE51. Also, due to characteristics of the route measured with mobile devices, BC(ATN) plot alone was not enough to determine the level of the loading effect for MA200 instruments. Since each run started at the rural background with lower eBC concentrations, continuing towards the village, where concentrations were usually higher, the BC(ATN) plot was biased. Therefore, two different measures had to be considered in order to determine the filter loading effect:

- Observed jump in measured concentration after the tape advance should be minimized after the correction for the loading effect.

- Considering the contribution of sources at both stations, rural background and village, and measurements obtained by the AE33, the absorption Angström exponent (AAE) is expected to increase from the rural background toward the village. Therefore, the compensation should not result in decrease of AAE with ATN.

\section{Analysis}

Correlation analyses were performed to determine the comparability of the mobile with the reference instruments. For the IC of the mobile devices against each other (MA200 vs. MA200; AE51 vs. AE51; MA200 vs. AE51), a reduced major axis (RMA) regression was used to include errors in both instruments. For the IC of the mobile devices against the reference absorption photometers in different environments a simple linear regression was applied. We also investigated the impact of different parameters (i.e. location, time of day, filter loading effect correction, and duration of IC) to the intercomparability of the instruments.

More information on the performance of the AE51 during these campaigns (time series, etc.) are already published in Alas et al. (2018) (Supplementary Material), Costabile et al. (2017), and Alas et al. (2019).

All calculations were performed in $\mathrm{R}$ ( $\mathrm{R}$ Core Team, 2019) using lmodel2 (Legendre, 2018) and lme4 (Bates et $a l ., 2015)$ packages. Data manipulation was done using the package dplyr (Wickham et al., 2018). For the visualizations, ggplot2 (Wickham, 2016) package was used.

\section{RESULTS AND DISCUSSION}

\section{Unit-to-unit Comparability of AE51}

For campaigns in Rome and Loški Potok, two aerosol backpacks with identical instrumentation were used to explore the unit-to-unit variability of two AE51 units in realworld MM. The models used were the AE51 S5 and AE51 S6, where the former is an older model.

Fig. 1 shows the correlation analyses (RMA) between the two models during both campaigns. It must be noted that exactly the same models were used for both campaigns. The correlation of the two units is slightly lower in the Rome campaign compared to the Loški Potok campaign. In Rome campaign, The AE51 S5 was 5\% lower than the AE51 S6. This can be attributed to the study area in Rome, which was in an urban area with higher variabilities of sources. Nonetheless, 
(a)

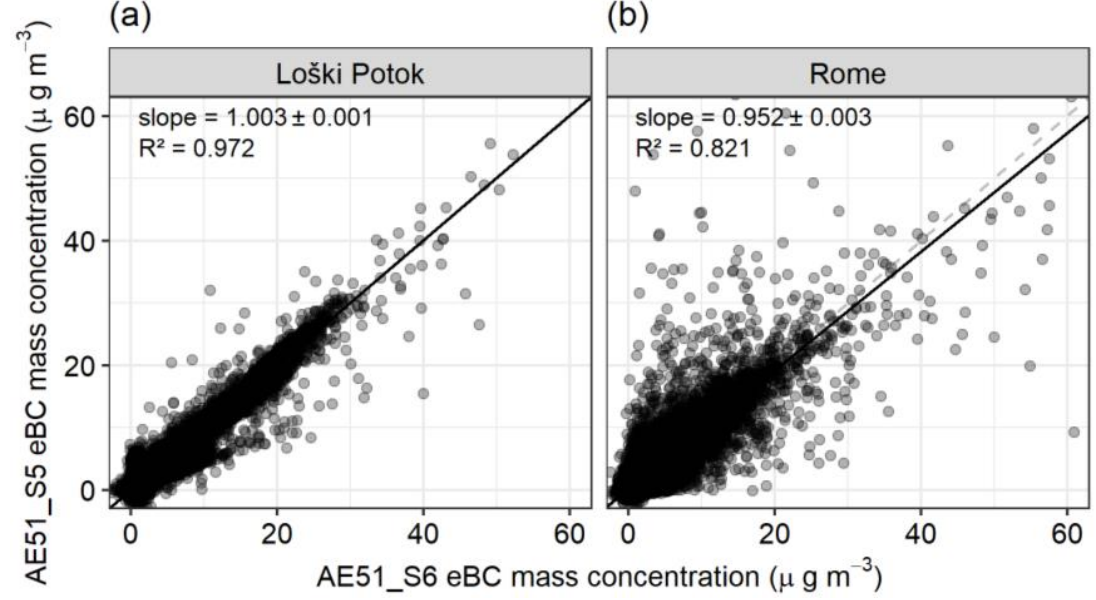

Fig. 1. Intercomparison for eBC mass concentrations (10-second median) measured by the AE51 S6 and AE51 S5 during the collocated MM in (a) Loški Potok, Slovenia and (b) Rome, Italy. Data were taken from two backpacks with identical instrumentation running simultaneously, side by side for each run, throughout the campaign. RMA regression was used to fit the two measurements. For IC details, see Tables 2, S1, S2, S3, and S4.

the unit-to-unit variability of the two AE51 units during MM is low at around $5 \%$ at 10 -second time resolution.

\section{Intercomparability of Mobile Devices to Reference Instruments in Different Environments}

In this section, we explore how the AE51 performed in different environments using data from three different campaigns in comparison to rack-mounted, widely used absorption photometers (MAAP 5012 and AE33), which are considered as reference instruments. The AE51 measurements were aggregated to 1-minute averages to compare against the reference instruments with 1-minute time resolution. The entire IC dataset for each campaign was used for this correlation analysis and the results are shown in Fig. 2. From this figure, it appears that the AE51s performed best in Rome, followed by Loški Potok, and lastly in Manila. To determine which other factors may have influenced the correlations, the following parameters were investigated: i) the location of IC, ii) the correction of the filter loading effect, iii) the time of the day when IC was conducted, and iv) the duration of IC.

\section{Location of IC}

The Manila and Loški Potok campaigns had multiple locations for IC. For Manila, IC was done at an urban background site, one at a street side, and one at a street canyon. For Loški Potok, one was done at a rural background region (up a hill) and one at a street side of a rural village. We performed the correlation analysis again, this time not only as a function of the study area, but also of where the IC was performed (Fig. 3). One can see now that, for Manila (Fig. 3(a)), the low correlation $\left(\mathrm{R}^{2}<0.5\right.$, and slope $=0.75$ and 1.5) between the AE51 and MAAP was due to the IC done at the street side and street canyon. At the urban background region, the correlation is high $\left(\mathrm{R}^{2}>0.8\right.$, slope $>$ 0.8). In Rome, IC was only done at an urban background area so the results are the same as in Fig. 2(b). Fig. 3(c) also shows good correlation between the mobile and reference instruments, indicating that the area of Loški Potok has a homogenous distribution of eBC particles. The poor correlation at street side IC in Manila is due to the higher variabilities that arise from passing of vehicles, turbulence, and other local sources as well as the vertical and horizontal distance between the inlets of the aerosol backpack and aerosol container. Although, this does not mean that the AE51 do not perform well in areas with high spatial variabilities, it is simply difficult to conduct an IC in such locations due to rapidly fluctuating concentrations. This could be improved by connecting the backpack to the same inlet as the reference instrument, but this would disrupt the MM. Therefore, to harmonize mobile instruments during mobile measurement campaigns, IC done at atmospherically homogenous areas work best.

\section{The Filter-loading Effect}

All datasets were analyzed for FLE. From the three datasets, the measurements from both AE51 and MA200 of the Loški Potok campaign were corrected for the FLE. For the Manila and Rome datasets, the results of the three assessment approaches are presented and discussed here. From the first approach, the BC(ATN) plots showed a dependency on the route (Figs. S1 and S3), indicating that a single loading parameter $\mathrm{k}$ cannot be derived, because the area being studied has a very inhomogeneous atmosphere and specific areas with different sources have to be analyzed separately. Unfortunately, there isn't sufficiently large data set to derive an empirical k (Fig. S2). The deviation (ATN) approach showed similar results (Fig. S4) to the first one. For the Katipunan route (Figs. S4(a) and S4(b)), the ratio vs. ATN plots shows a negative slope $(-0.0063)$ while the difference vs. ATN has a positive slope (0.661). The Taft route (Figs. S4(c) and S4(d)) shows negative slopes for both the ratio $(-0.00117)$ and the difference $(-0.215)$. This is more indicative of an FLE. The Rome route (Figs. S4(e) and S4(f)) shows positive slopes as well (0.0028 and 0.0039). However, this approach may not be suitable for this study: 
(a)

$$
\text { ? }
$$

(b)

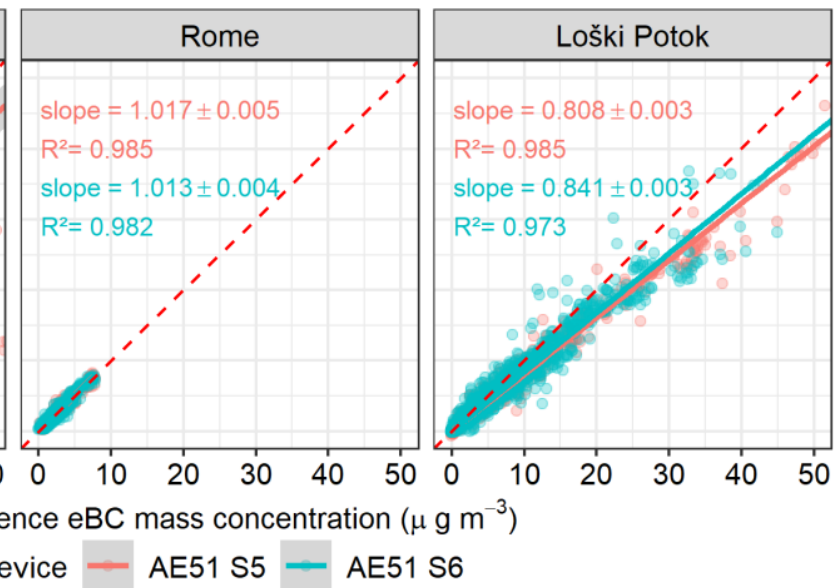

Fig. 2. Intercomparison between the AE51 units against the reference eBC mass concentration measurements at three different study areas: (a) Manila, Philippines, (b) Rome, Italy, and (c) Loški Potok, Slovenia. The time resolution is 1 minute and OLS method forced through the origin was used for fitting. Data were taken from IC done during the mobile measurement runs when the runners were passing by the vicinity of the aerosol container and the backpacks were placed near it. For this, IC periods in all sites were combined into their respective cities. For IC details, see Tables 2, S1, S2, S3, and S4.

the IC periods (co-located AE51 and reference measurements) were performed in the middle of the run - this means, that we would have only a fraction of the ATN range to analyze. To be able to apply results from this approach, we would need eBC mass concentration data that is evenly distributed over the whole ATN range, otherwise, it would be misleading to use a $\mathrm{k}$ derived from this and apply it to the whole measurement route in urban areas. For the third approach, a value of 0.005 for $\mathrm{k}$ based on literature (Drinovec et al. 2017) was used, representing a roadside aerosol for $880 \mathrm{~nm}$. This was applied using the algorithm proposed by Virkkula et al. (2007). Fig. S5 shows that correcting for the FLE with the given $\mathrm{k}$ did not significantly improve the eBC mass concentrations of the AE51 (3-8\% increase).

Also, owing to the inhomogeneity of the study area, correcting the whole dataset with a single k may cause an over/underestimation in specific parts of the route. Unlike in Loški Potok, which is a rural area, the eBC levels vary widely and rapidly in urban environments due to micrometeorology and high spatial variation of sources and their strengths. These variations are also greater than the possible error caused by the FLE. Hence, correcting for it will not lead to any significant improvement of the AE51 eBC measurements.

Results of the three approaches suggest that there are no significant detectable FLE in the Manila and Rome datasets. Dedicated experiments are necessary to develop methods that would lead to derivation of a loading parameter appropriate for data obtained from MM in urban areas.

In this section, the impact of the FLE correction on the Loški Potok data is discussed. Fig. 4 shows the IC between the AE51 and the AE33 in the two 1C locations in Loški Potok for both uncorrected and corrected AE51 eBC data. The correlations between uncorrected $\mathrm{eBC}$ measured by microAethalometers (AE51_S5 and AE51_S6) and the reference instrument AE33 were good at both stations, rural background and rural village, as seen on Fig. 4 (red points).
The slope of uncorrected eBC measurements for both mobile instruments was higher at the urban background station (0.88) than for the village station. This can be explained by taking a closer look into the course of each run, since every single run started at the rural background, where the attenuation of the filter was low, continuing towards the village, where filter attenuation was already high. This leads to increased loading effect and consequently lower slope, when comparing to the reference AE33 in the village: 0.81 and 0.84 for the AE51 S5 and AE51 S6, respectively (Fig. 4II.). The same loading effect correction $(\mathrm{k}=0.005$, also representative of freshly emitted particles from wood burning (Drinovec et al., 2017)) was applied for the whole course of mobile run with the AE51. This procedure improved the agreement between both instruments (AE51 and AE33) with slopes close to unity: 0.92 (S5) and 0.93 (S6) at the rural background and 0.95 (S5) and 0.96 (S6) in the rural village. Variability and level of eBC concentrations was lower at the rural background than at the rural village station, owing to more distant emission sources with lower variability at the rural background station.

\section{Time of IC}

The time of the day when the IC was performed was also investigated (Fig. 5) to determine if the intercomparability of the AE51 and reference instruments is affected by the variability of the meteorological conditions and sources within a day. The time of IC was segregated to morning, afternoon, and evening as proxy to variations in incoming solar radiation, temperature, and height of boundary layer. Fig. 5 shows that there is no obvious dependence of the intercomparability to the time of IC. In all IC locations, the AE51s were able to capture the eBC mass concentrations regardless of the variabilities within the day.

\section{Duration of IC}

Lastly, the duration of IC was investigated. Only data 
(a)
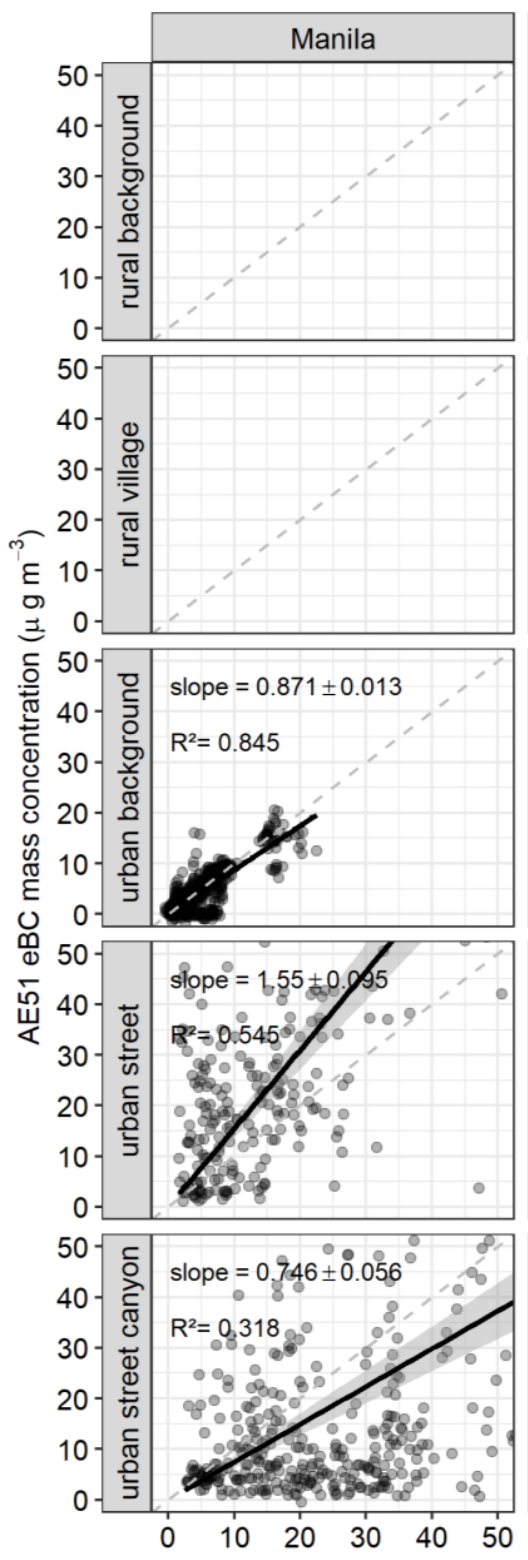

(b)
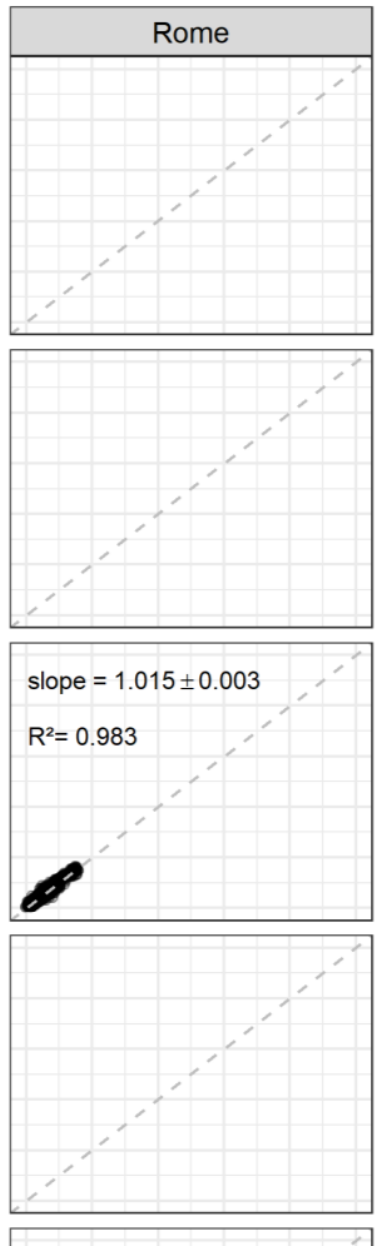

(c)
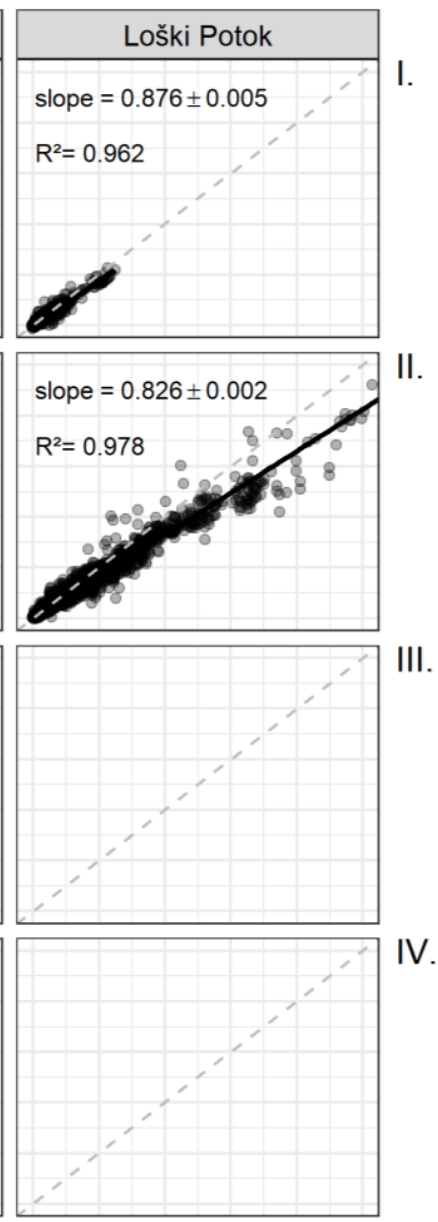

IV.

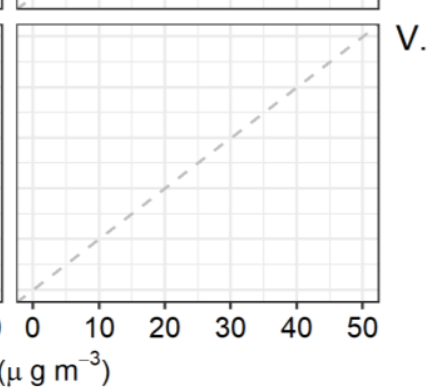

Fig. 3. Intercomparison between the AE51 units against the reference eBC mass concentration measurements as a function of location of IC ((I) rural background, (II) rural village, (III) urban background, (IV) urban street and (V) urban street canyon) per study area ((a) Manila, (b) Rome, and (c) Loški Potok). This is basically the same as in Fig. 2, but now also segregated into different IC locations. For IC details, see Tables 2, S1, S2, S3, and S4.

from rural background, rural village, background and urban background regions were used for this analysis which is shown in Fig. 6. The duration of IC increases from Figs. 6(a) to $6(d)$ and it shows that longer IC durations lead to better correlation and harmonization of the mobile with the reference instruments. Longer durations provided more time for the mobile instruments to adjust to its surroundings as they are not in the same inlet as the reference instruments nor are they on the same height from the ground. Therefore, IC should be done for more than 10 minutes in atmospherically homogenous areas to achieve better harmonization between the mobile and reference instruments.

\section{MA200}

For the Loški Potok campaign, the 2 backpacks were equipped with both an AE51 and the new generation, 5wavelength microAethalometer MA200. This served as a field performance test of the MA200 in extreme conditions (winter) in terms of unit-to-unit variability, IC against AE51 and finally, IC against the AE33.

\section{Unit-to-unit}

Fig. 7 shows the results of the RMA regression between the two units of MA200 for all wavelengths (uncorrected data). The two units have good agreement with each other 
(a)

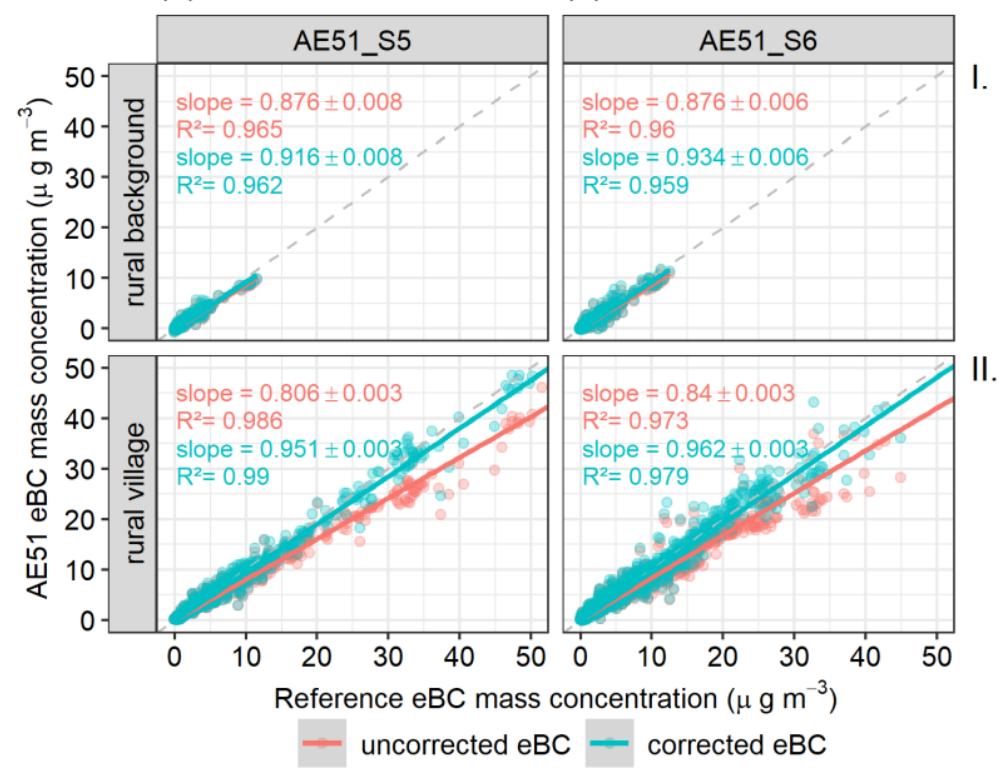

(b)

II.

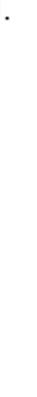

Fig. 4. Intercomparison of eBC measurements of AE51 against AE33 at the Loški Potok campaign before (red: uncorrected) and after (blue: corrected) filter-loading effect correction. Data were taken from IC done during the mobile measurement runs when the runners were passing by the vicinity of the aerosol container and the backpacks were placed near it. For IC details, see Tables 2, S1, S2, S3, and S4.

except for the blue channel $(470 \mathrm{~nm})$ where the $R^{2}$ is 0.57 which could be due to the noise from the light source. In this experiment, the MA200 was also compared against AE51. The MA200_75 was in the same backpack as the AE51_S5, both downstream of the silica gel dryer. The same is true for the MA200_69 and AE51_S6. Fig. 8 shows the correlation between the MA200 (880 nm channel) and AE51 during $\mathrm{MM}$ at Loški Potok with $\mathrm{R}^{2}$ and slopes higher than 0.90. The real-world eBC mass concentrations measured by the MA200 at $880 \mathrm{~nm}$ correlates well with the measurements from the AE51.

\section{Against Reference Instrument}

Since the AE33 and the MA200 do not have the same number of wavelengths, the MA200 was compared to only 5 channels of the AE33 which are listed in Table 3. In addition, since the software versions of the MA200s still did not include the filter-loading correction algorithm, the data were post-processed for the filter-loading effect with the offline method of Virkkula et al. (2007) as explained in the Methods section. Fixed k (compensation; from here on k_MA200) parameters characterizing the loading effect were determined from the measurement data, separately for each wavelength. k_MA200 values used for loading effect compensation are listed in Table 3. The data from AE33 were already corrected online.

The IC of measurements obtained with the MA200 and the reference AE33 for five different wavelengths (UV, Blue, Green, Red and IR) at two stations in Loški Potok, showed a more pronounced filter-loading effect in MA200 instruments as compared to the AE51. Moreover, higher loading effect is seen for the lower wavelengths (Fig. 9).

Correcting for the filter-loading effect in MA200 made a significant improvement of the correlation against AE33 for all wavelengths, particularly for lower wavelengths. Less loading effect was observed for the rural background station, due to low filter attenuation at the beginning of each run. The slope between datasets for the UV wavelength increased after compensation from $>0.29$ to $>0.78$, with an increase of the $\mathrm{R}^{2}$ from $>0.80$ to $>0.93$. For the IR wavelength, the improvement of correlation with corrected data was the smallest, yet with an important increase of the slope at the rural village site from $>0.74$ to $>0.87$. The loading parameter k_MA200 differs from the one featured in other Aethalometer instruments due to a completely different filter material - it is not fibrous but rather a membrane. Loading effect for Teflon-coated glass fiber filters is mostly known, whereas this is one of the first studies, where the loading effect for MA200 instruments is evaluated. As observed during the Loški Potok campaign, MA200 instrument experiences much stronger loading effect than the AE51. Therefore, loading compensation should be applied to the raw data especially with high filter loading and when AAE is calculated from the multi-wavelength data, since stronger loading effect in low wavelengths leads to biased values of AAE.

\section{CONCLUSIONS}

microAethalometers, despite being widely-used for mobile measurements of eBC mass concentrations, have hardly been assessed in real-world environments. In this study, two models (AE51 and MA200) were assessed to determine how well they perform in the field during mobile measurements when compared against a reference absorption photometer.

Data from three mobile measurement campaigns were used in this study: a highly urbanized megacity during the 
(a)
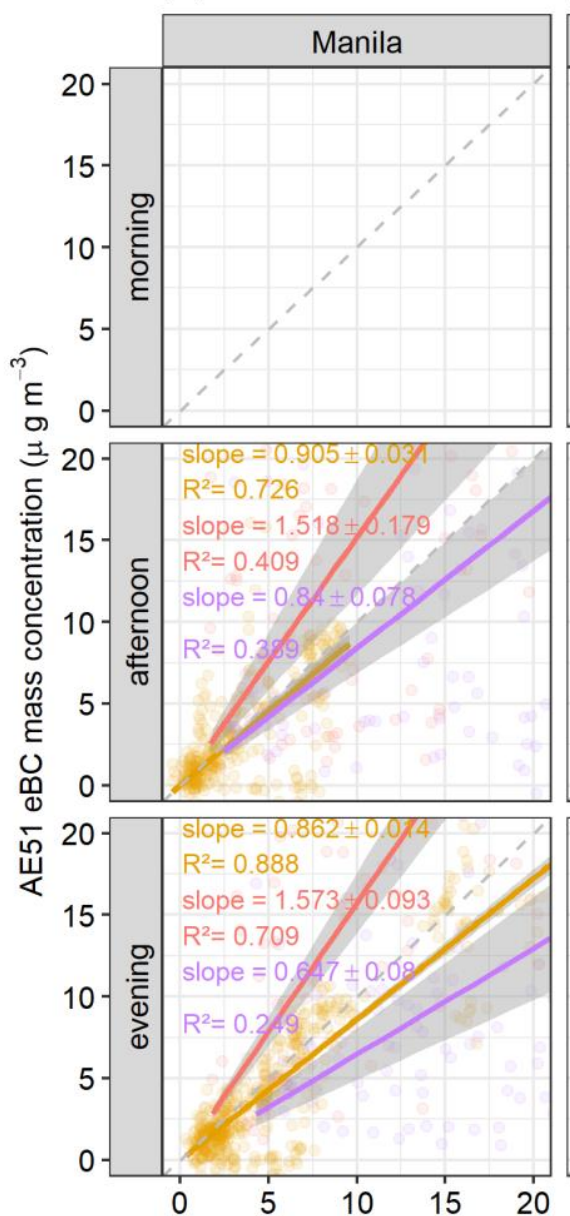

(b)
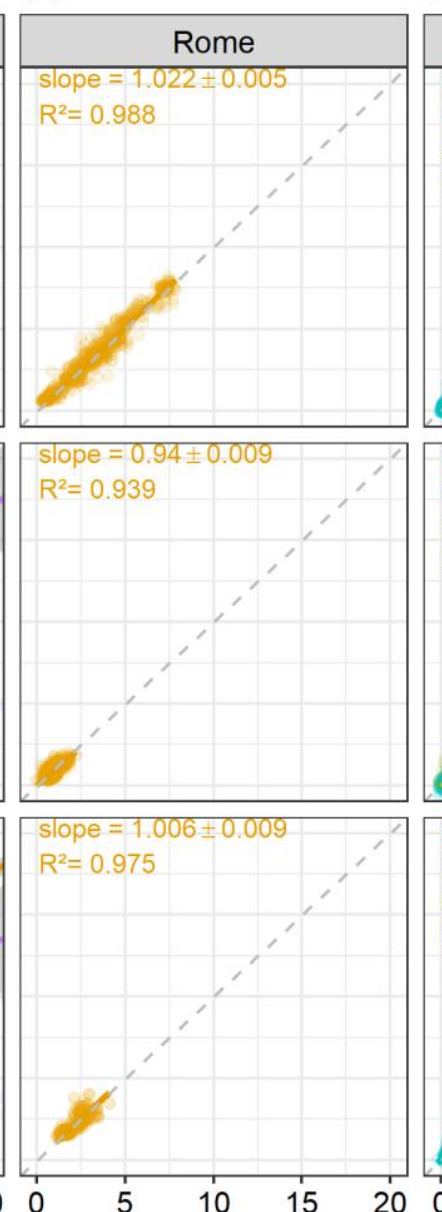

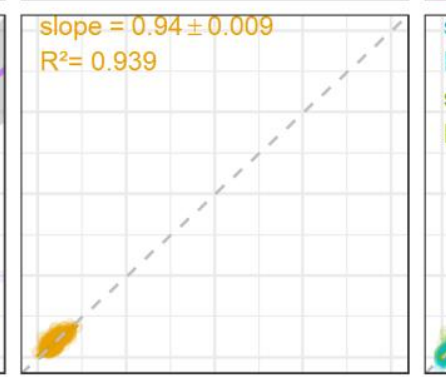

(c)

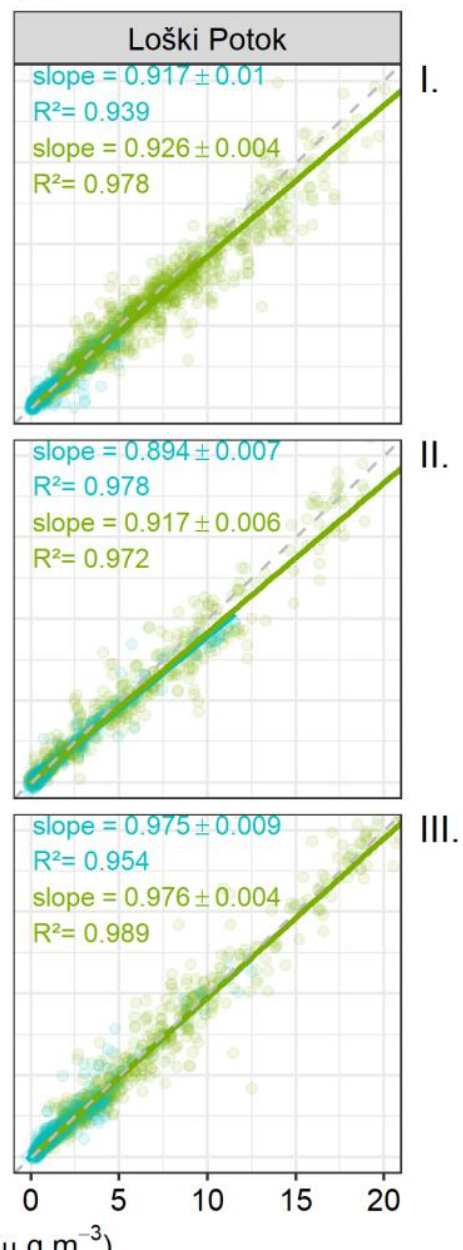

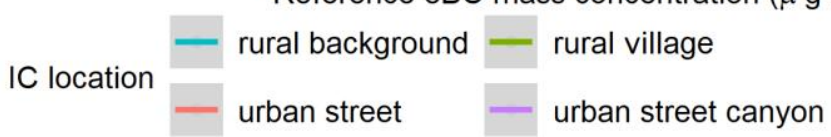

urban background

Fig. 5. Intercomparison between AE51 and reference instrument as a function of IC location (colors) and time of IC: (I) morning, (II) afternoon, and (III) evening. The columns correspond to study area: (a) Manila, (b) Rome, (c) Loški Potok. For IC details, see Tables 2, S1, S2, S3, and S4.

summer (Manila, Philippines), a touristic but urbanized city in winter (Rome, Italy), and a rural village in winter (Loški Potok, Slovenia). The assessment was in terms of its comparability against another unit of the same model, and a reference absorption photometer.

The AE51 showed a unit-to-unit variability of 5\% in urban areas, and lower in rural areas. This was also reflected by the intercomparison (IC) against the reference instruments, where $\mathrm{R}^{2}$ are higher and slopes closer to unity for IC's done at the rural background, rural village, background, and urban background locations than at urban street and urban street canyon. The intercomparability of the AE51 to the reference instruments showed dependence on the location of the IC, filter-loading effect correction, and duration of IC, but not on the time of day when the IC was done. This implies that the AE51 performs well in different environments and can capture the variabilities of the $\mathrm{eBC}$ mass concentrations within the day which are caused by the varying strength of sources and meteorological conditions. Also, for mobile measurements, harmonization of the AE51 with the reference instruments should be done in an atmospherically homogenous environment at longer duration (10-30 minutes) where the spatial variabilities are much lesser than at the street side.

In addition, the field performance of a newer microAethalometer with 5-wavelengths (MA200) was also assessed in terms of its intercomparability against another MA200, the AE51, and a 7-wavelength Aethalometer. The MA200 has low unit-to-unit variability ( 2\%) across all wavelengths as determined at the rural sites. The variability is greater at the rural village, especially at lower wavelengths $(\mathrm{UV}=15-22 \%$, blue $=12-18 \%$, green $=11-15 \%$, red $=0$ $8 \%$, and red $=0-3 \%$ ). The MA200s ( $880 \mathrm{~nm}$ channel) showed good agreement with the AE51s. In the environments with similar conditions as in Loški Potok, where biomass burning is an important source of $\mathrm{eBC}$, correcting the raw data for filter-loading effect is of exceptional importance for reliable 
(a)

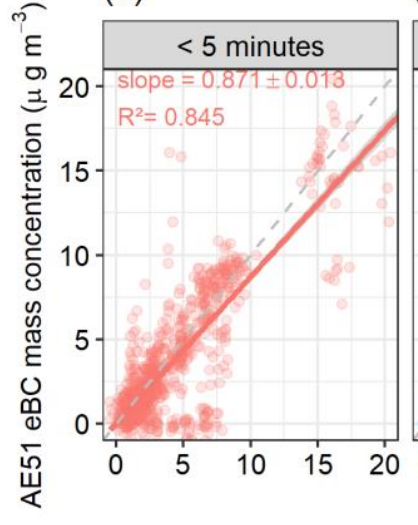

(b)

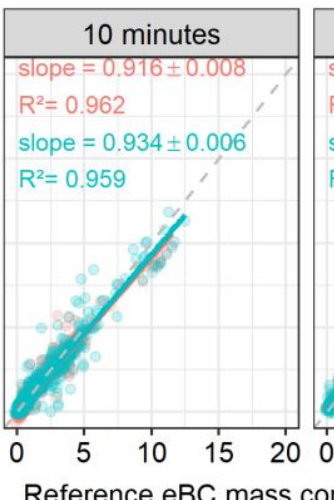

(c)

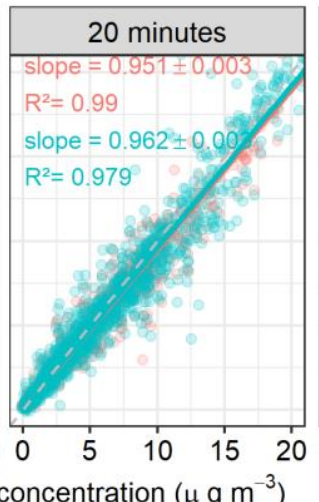

(d)

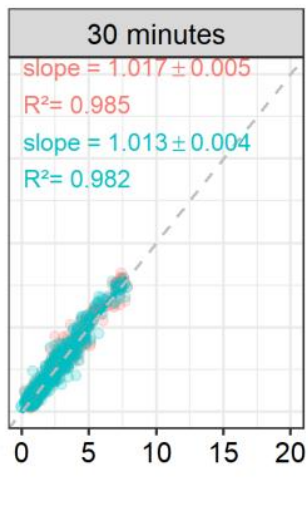

$$
\text { AE51_S5 - AE51_S6 }
$$

Fig. 6. Intercomparison between AE51 and reference instrument as a function of duration of IC: (a) < 5 minutes, (b) 10 minutes, (c) 20 minutes, and (d) 30 minutes. The colors correspond to the models of AE51. For IC details, see Tables 2, S1, S2, S3, and S4.

(a)

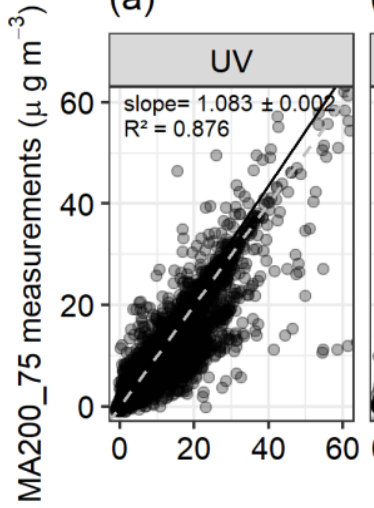

(b)

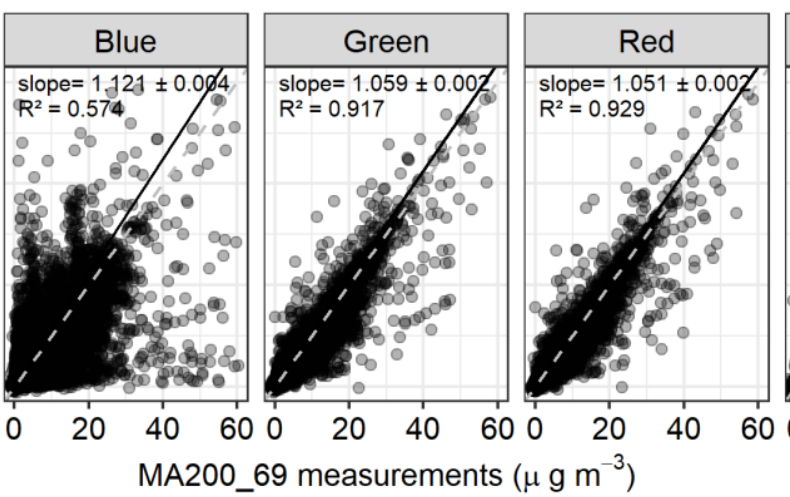

(e)

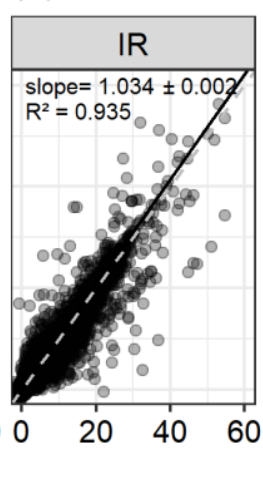

Fig. 7. Intercomparison between the measurements (10-second median, uncorrected) from the MA200_75 and MA200_69 for all wavelengths $(\mathrm{a}-\mathrm{e})$ during the collocated MM in Loški Potok, Slovenia. RMA regression was used for fitting. For IC details, see Tables 2, S1, S2, S3, and S4.

Table 3. Channels (wavelengths) used to compare MA200 (5 wavelengths) measurements with AE33 (7 wavelengths) with the loading parameter values derived for each wavelength of the MA200 denoted as k_MA200.

\begin{tabular}{llll}
\hline & MA200 $(\mathrm{nm})$ & AE33 $(\mathrm{nm})$ & k_MA200 \\
\hline UV & 375 & 370 & 0.03 \\
Blue & 470 & 470 & 0.024 \\
Green & 528 & 520 & 0.0215 \\
Red & 625 & 660 & 0.0156 \\
IR & 880 & 880 & 0.015 \\
\hline
\end{tabular}

data interpretation. In the study in Loški Potok, Slovenia, loading parameter $\mathrm{k}$ was determined for each wavelength and applied with the post-processing method (Virkkula et al., 2007) assuming a constant $\mathrm{k}$ value for the whole winter measurement period. This assumption can introduce systematic errors in the data, which can be avoided by determining highly changing $\mathrm{k}$ values using the online algorithms (e.g., Drinovec et al., 2015, 2017). In addition, further laboratory, as well as real-world experiments, are necessary to obtain a range of $\mathrm{k}$ values characteristic for MA200 instrument.

Further investigations on the field performance of the MA200, similar to the ones done for the AE51 in this study, especially in other environmental conditions, is necessary to fully assess its capabilities in reliably capturing the spatial variability of eBC mass concentrations.

Loading effect on eBC measurements done at urban areas in the context of mobile measurements proved challenging to detect as the relationship between eBC and ATN showed dependency on the route. Dedicated experiments have to be done to develop a method capable of detecting loading effect and apply an offline correction on the eBC measured through mobile measurements.

Finally, the AE51 and the MA200 are reliable instruments that can perform well in drastically different environments. Fully understanding the how these instruments perform in the field can increase our confidence in the data gathered through mobile measurements which are necessary for accurate personal exposure estimates and air pollution mapping. 
(a)?

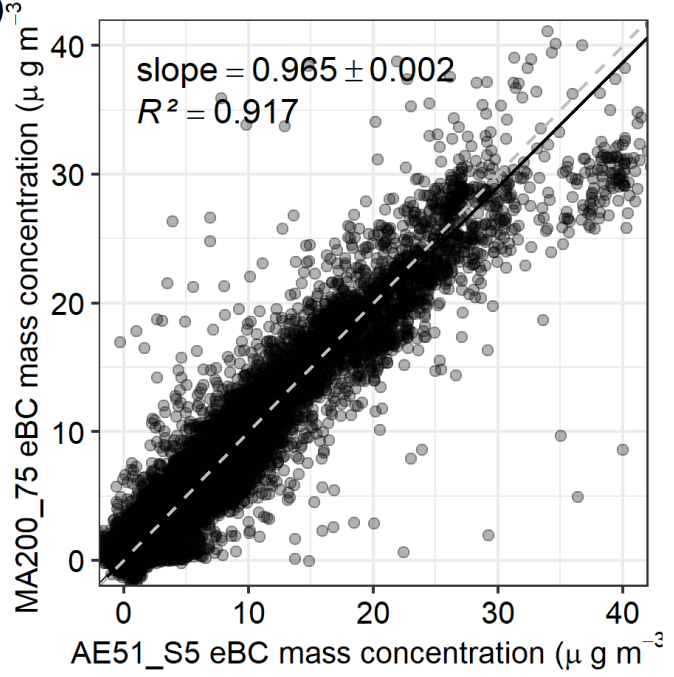

(b)

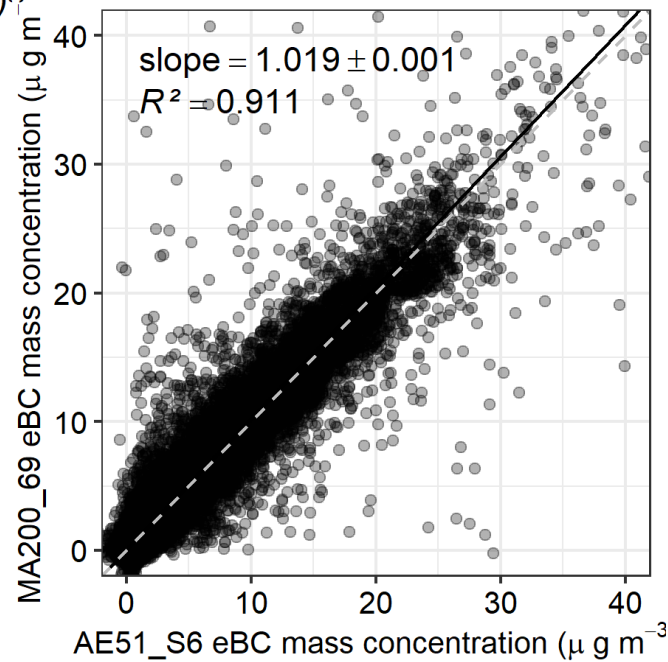

Fig. 8. Intercomparison between the eBC mass concentrations (10-second median; uncorrected) measured by the MA200 units (at $880 \mathrm{~nm}$; uncorrected) against the AE51 units during the collocated MM in Loški Potok, Slovenia. RMA regression was used for fitting. For IC details, see Tables 2, S1, S2, S3, and S4.

(a)
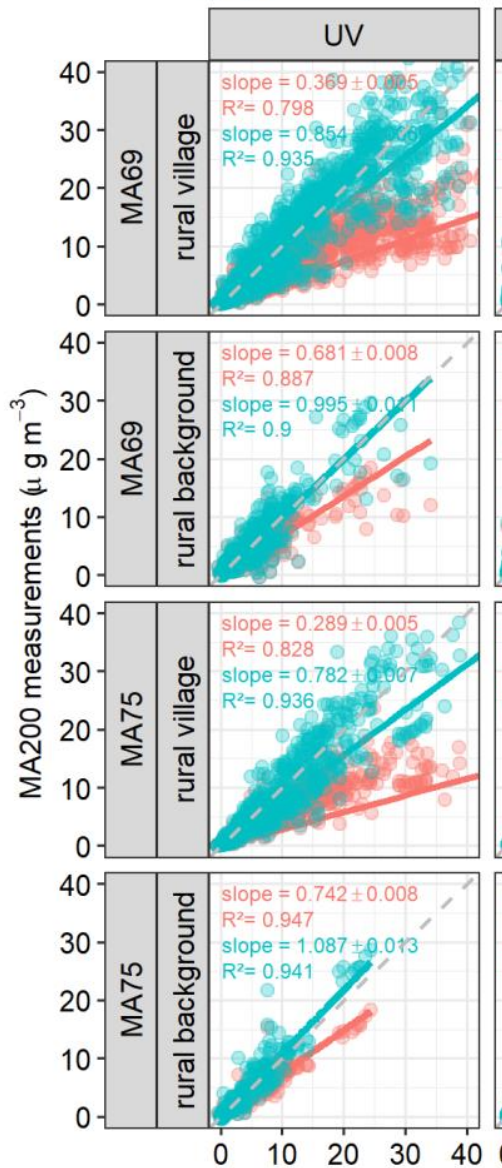

(b)
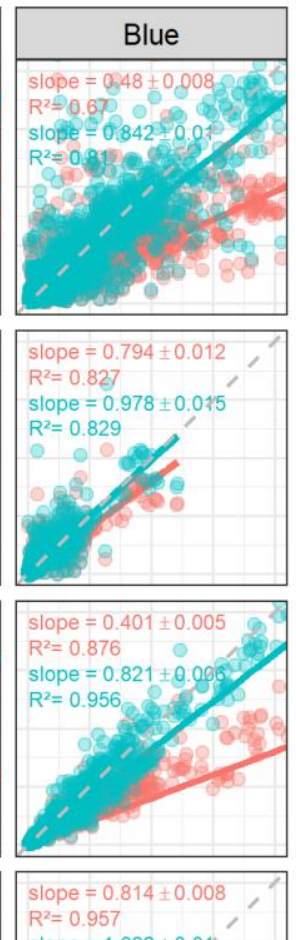

slope $=1.02$

$R^{2}=0.957$ (c)
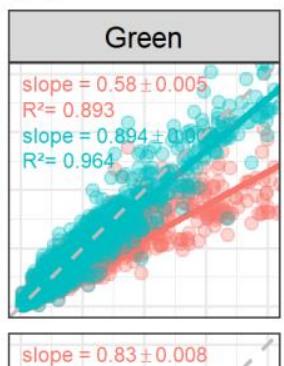

\section{$R^{2}=0.931$}

slope $=0.976+0.008$

$\mathrm{R}^{2}=0.93$
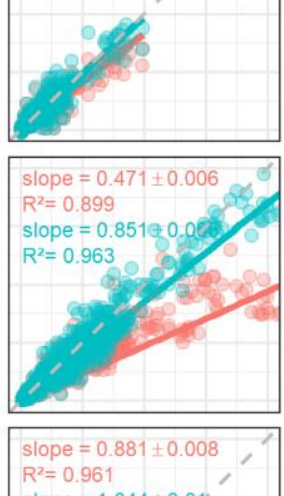

$R^{2}=0.961$

$\mathrm{R}^{2}=0.962$ (d)
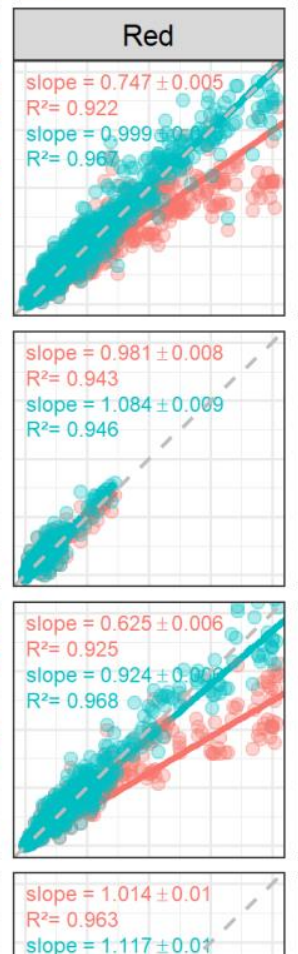

$\mathrm{R}^{2}=0.964$

$R^{2}=0.96$

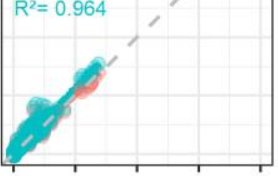

$\begin{array}{lllllllll}10 & 20 & 30 & 40 & 0 & 10 & 20 & 30 & 40\end{array}$

slope $=1.076 \pm 0.0 \%$

$R^{2}=0.964$

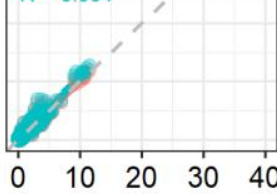

(e)
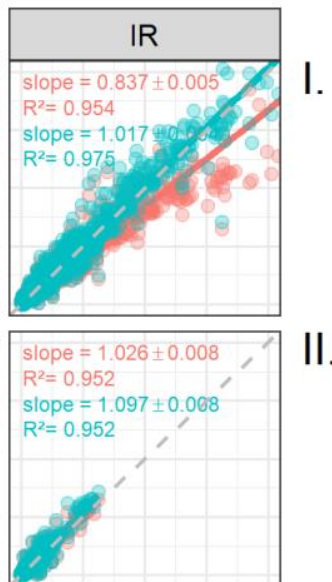

III.
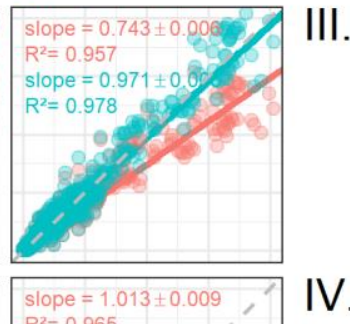

IV.

II.

AE33 measurements $\left(\mu \mathrm{g} \mathrm{m}^{-3}\right)$

status $=$ uncorrected $\mathrm{eBC}=$ corrected $\mathrm{eBC}$

Fig. 9. Intercomparison of the measurements from the each MA200 ((I) and (II) for MA69, (III) and (IV) for MA75, for each IC location (rural village and rural background). The red and blue dots represent uncorrected and corrected measurements. For IC details, see Tables 2, S1, S2, S3, and S4. 


\section{ACKNOWLEDGMENTS}

Authors from the LP-2018 campaign would like to thank the following: Slovenian Research Agency, Municipality of Loški Potok, Environment Agency of Republic of Slovenia, and the grant from COST Action CA16109 COLOSSAL. Authors from the CARE-2017 campaign acknowledge: Antonio di Ianni, Dr. Luca di Liberto, and Dr. Gian Paolo Gobbi. Authors from the MACE-2015 campaign acknowledge: Dr. James Simpas, Dr. Mylene Cayetano, Dr, Edgar Vallar, Dr. Wolfram Birmili, Dr. Simonas Kecorius, Everlyn Tamayo, and Leizel Madueño. This work was done under the project 19ENV08 AEROMET II, which has received funding from the EMPIR programme co-financed by the Participating States and from the European Union's Horizon 2020 research and innovation programme. We acknowledge the efforts of the all the people and institutes involved in the three campaigns.

\section{DISCLAIMER}

Reference to any companies or specific commercial products does not constitute endorsement by the authors and their affiliations.

\section{SUPPLEMENTARY MATERIAL}

Supplementary data associated with this article can be found in the online version at https://doi.org/10.4209/aaqr.2 020.03.0113

\section{REFERENCES}

Alas, H.D., Müller, T., Birmili, W., Kecorius, S., Cambaliza, M.O., Simpas, J.B.B., Cayetano, M., Weinhold, K., Vallar, E., Galvez, M.C. and Wiedensohler, A. (2018). Spatial characterization of black carbon mass concentration in the atmosphere of a southeast Asian megacity: An air quality case study for Metro Manila, Philippines. Aerosol Air Qual. Res. 18: 2301-2317. https://doi.org/10.4209/aaqr.2 017.08.0281

Alas, H.D.C., Weinhold, K., Costabile, F., Di Ianni, A., Müller, T., Pfeifer, S., Di Liberto, L., Turner, J.R. and Wiedensohler, A. (2019). Methodology for high quality mobile measurement with focus on black carbon and particle mass concentrations. Atmos. Meas. Tech. 12: 4697-4712. https://doi.org/10.5194/amt-12-4697-2019

Apte, J.S., Kirchstetter, T.W., Reich, A.H., Deshpande, S.J., Kaushik, G., Chel, A., Marshall, J.D. and Nazaroff, W.W. (2011). Concentrations of fine, ultrafine, and black carbon particles in auto-rickshaws in New Delhi, India. Atmos. Environ. 45: 4470-4480. https://doi.org/10.1016/j.atmos env.2011.05.028

Bates, D., Mächler, M., Bolker, B. and Walker, S. (2015). Fitting linear mixed-effects models using lme4. J. Stat. Software 67:1-48. https://doi.org/10.18637/jss.v067.i01

Birmili, W., Rehn, J., Vogel, A., Boehlke, C., Weber, K. and Rasch, F. (2013). Micro-scale variability of urban particle number and mass concentrations in Leipzig, Germany. Meteorol. Z. 22: 155-165. https://doi.org/10.1127/09412948/2013/0394

Cai, J., Yan, B., Kinney, P.L., Perzanowski, M.S., Jung, K.H., Li, T., Xiu, G., Zhang, D., Olivo, C., Ross, J., Miller, R.L. and Chillrud, S.N. (2013). Optimization approaches to ameliorate humidity and vibration related issues using the microaeth black carbon monitor for personal exposure measurement. Aerosol Sci. Technol. 47: 1196-1204. https://doi.org/10.1080/02786826.2013. 829551

Cheng, Y.H. and Lin, M.H. (2013). Real-time performance of the microAeth ${ }^{\circledR}$ AE51 and the effects of aerosol loading on its measurement results at a traffic site. Aerosol. Air Qual. Res. 13: 1853-1863. https://doi.org/10. 4209/aaqr.2012.12.0371

Costabile, F., Alas, H., Aufderheide, M., Avino, P., Amato, F., Argentini, S., Barnaba, F., Berico, M., Bernardoni, V., Biondi, R., Casasanta, G., Ciampichetti, S., Calzolai, G., Canepari, S., Conidi, A., Cordelli, E., Di Ianni, A., Di Liberto, L., Facchini, M., Facci, A., Frasca, D., Gilardoni, S., Grollino, M., Gualtieri, M., Lucarelli, F., Malaguti, A., Manigrasso, M., Montagnoli, M., Nava, S., Perrino, C., Padoan, E., Petenko, I., Querol, X., Simonetti, G., Tranfo, G., Ubertini, S., Valli, G., Valentini, S., Vecchi, R., Volpi, F., Weinhold, K., Wiedensohler, A., Zanini, G., Gobbi, G. and Petralia, E. (2017). First results of the "Carbonaceous Aerosol in Rome and Environs (CARE)" experiment: Beyond current standards for $\mathrm{PM}_{10}$. Atmosphere 8: 249. https://doi.org/10.3390/atmos8120249

Dons, E., Temmerman, P., Van Poppel, M., Bellemans, T., Wets, G. and Int Panis, L. (2013). Street characteristics and traffic factors determining road users' exposure to black carbon. Sci. Total Environ. 447: 72-79. https://doi.org/10.1016/j.scitotenv.2012.12.076

Drinovec, L., Močnik, G., Zotter, P., Prévôt, A.S.H., Ruckstuhl, C., Coz, E., Rupakheti, M., Sciare, J., Müller, T., Wiedensohler, A. and Hansen, A.D.A. (2015). The "dual-spot" aethalometer: An improved measurement of aerosol black carbon with real-time loading compensation. Atmos. Meas. Tech. 8: 1965-1979. https://doi.org/10.519 4/amt-8-1965-2015

Drinovec, L., Gregorič, A., Zotter, P., Wolf, R., Bruns, E.A., Prévôt, A.S.H., Petit, J.E., Favez, O., Sciare, J., Arnold, I.J., Chakrabarty, R.K., Moosmüller, H., Filep, A. and Močnik, G. (2017). The filter-loading effect by ambient aerosols in filter absorption photometers depends on the coating of the sampled particles. Atmos. Meas. Tech. 10: 1043-1059. https://doi.org/10.5194/amt-10-1043-2017

Düsing, S., Wehner, B., Müller, T., Stöcker, A. and Wiedensohler, A. (2019). The effect of rapid relative humidity changes on fast filter-based aerosol-particle light-absorption measurements: Uncertainties and correction schemes. Atmos. Meas. Tech. 12: 5879-5895. https://doi.org/10.5194/amt-12-5879-2019

Glojek, K., Gregorič, A. and Ogrin, M. (2018). Black carbon air pollution - Case study of Loski Potok. Dela 50: 25-43. https://doi.org/10.4312/dela.50.5-43 
Good, N., Molter, A., Peel, J.L. and Volckens, J. (2017). An accurate filter loading correction is essential for assessing personal exposure to black carbon using an aethalometer. J. Exposure Sci. Environ. Epidemiol. 27: 409-416. https://doi.org/10.1038/jes.2016.71

Kecorius, S., Madueño, L., Vallar, E., Alas, H., Betito, G., Birmili, W., Cambaliza, M.O., Catipay, G., GonzagaCayetano, M., Galvez, M.C., Lorenzo, G., Müller, T., Simpas, J.B., Tamayo, E.G. and Wiedensohler, A. (2017). Aerosol particle mixing state, refractory particle number size distributions and emission factors in a polluted urban environment: Case study of Metro Manila, Philippines. Atmos. Environ. 170: 169-183. https://doi.org/10.1016/j. atmosenv.2017.09.037

Kecorius, S., Tamayo, E.G., Galvez, M.C., Madueño, L., Betito, G., Gonzaga-Cayetano, M., Vallar, E. and Wiedensohler, A. (2018). Activity pattern of school/university tenants and their family members in metro manila - philippines. Aerosol Air Qual. Res. 18: 2412-2419. https://doi.org/10.4209/aaqr.2018.02.0069

Kecorius, S., Madueno, L., Londahl, J., Vallar, E., Galvez, M.C., Idolor, L.F., Gonzaga-Cayetano, M., Muller, T., Birmili, W. and Wiedensohler, A. (2019). Respiratory tract deposition of inhaled roadside ultrafine refractory particles in a polluted megacity of south-east Asia. Sci. Total Environ. 663: 265-274. https://doi.org/10.1016/j. scitotenv.2019.01.338

Legendre, P. (2018). Lmodel2: Model II regression, 1.7-3 ed. Madueño, L., Kecorius, S., Birmili, W., Müller, T., Simpas, J., Vallar, E., Galvez, M.C., Cayetano, M., and Wiedensohler, A. (2019). Aerosol particle and black carbon emission factors of vehicular fleet in Manila, Philippines. Atmosphere 10: 603. https://doi.org/10.3390/ atmos 10100603

Masey, N., Ezani, E., Gillespie, J., Sutherland, F., Lin, C., Hamilton, S., Heal, M.R. and Beverland, I.J. (2020). Consistency of urban background black carbon concentration measurements by portable AE51 and reference AE22 aethalometers: Effect of corrections for filter loading. Aerosol Air Qual. Res. 20: 329-340. https://doi.org/10.4209/aaqr.2019.03.0145

Park, S.S., Hansen, A.D.A. and Cho, S.Y. (2010). Measurement of real time black carbon for investigating spot loading effects of aethalometer data. Atmos. Environ. 44: 1449-1455. https://doi.org/10.1016/j.atmosenv.2010. 01.025

Peters, J., Van den Bossche, J., Reggente, M., Van Poppel, M., De Baets, B. and Theunis, J. (2014a). Cyclist exposure to UFP and BC on urban routes in Antwerp, Belgium. Atmos. Environ. 92: 31-43. https://doi.org/10.1 016/j.atmosenv.2014.03.039

Petzold, A., Schloesser, H., Sheridan, P.J., Arnott, W.P., Ogren, J.A. and Virkkula, A. (2005). Evaluation of multiangle absorption photometry for measuring aerosol light absorption. Aerosol Sci. Technol. 39: 40-51. https://doi.org/10.1080/027868290901945
Petzold, A., Ogren, J.A., Fiebig, M., Laj, P., Li, S.M., Baltensperger, U., Holzer-Popp, T., Kinne, S., Pappalardo, G., Sugimoto, N., Wehrli, C., Wiedensohler, A. and Zhang, X.Y. (2013). Recommendations for reporting "black carbon" measurements. Atmos. Chem. Phys. 13: 8365-8379. https://doi.org/10.5194/acp-13-8365-2013

R Core Team (2019). R: A language and environment for statistical computing.

Rakowska, A., Wong, K.C., Townsend, T., Chan, K.L., Westerdahl, D., Ng, S., Močnik, G., Drinovec, L. and Ning, Z. (2014). Impact of traffic volume and composition on the air quality and pedestrian exposure in urban street canyon. Atmos. Environ. 98: 260-270. https://doi.org/10.1016/j.atmosenv.2014.08.073

Segura, S., Estellés, V., Titos, G., Lyamani, H., Utrillas, M.P., Zotter, P., Prévôt, A.S.H., Močnik, G., AladosArboledas, L. and Martínez-Lozano, J.A. (2014). Determination and analysis of in situ spectral aerosol optical properties by a multi-instrumental approach. Atmos. Meas. Tech. 7: 2373-2387. https://doi.org/10.519 4/amt-7-2373-2014

Van den Bossche, J., Peters, J., Verwaeren, J., Botteldooren, D., Theunis, J. and De Baets, B. (2015). Mobile monitoring for mapping spatial variation in urban air quality: Development and validation of a methodology based on an extensive dataset. Atmos. Environ. 105: 148161. https://doi.org/10.1016/j.atmosenv.2015.01.017

Van den Bossche, J., Theunis, J., Elen, B., Peters, J., Botteldooren, D. and De Baets, B. (2016). Opportunistic mobile air pollution monitoring: A case study with city wardens in antwerp. Atmos. Environ. 141: 408-421. https://doi.org/10.1016/j.atmosenv.2016.06.063

Viana, M., Rivas, I., Reche, C., Fonseca, A.S., Pérez, N., Querol, X., Alastuey, A., Álvarez-Pedrerol, M. and Sunyer, J. (2015). Field comparison of portable and stationary instruments for outdoor urban air exposure assessments. Atmos. Environ. 123: 220-228. https://doi.org/10.1016/j. atmosenv.2015.10.076

Virkkula, A., Makela, T., Hillamo, R., Yli-Tuomi, T., Hirsikko, A., Hameri, K. and Koponen, I.K. (2007). A simple procedure for correcting loading effects of aethalometer data. J. Air Waste Manage. Assoc. 57: 1214-1222. 3289.57.10.1214

Wickham, H. (2016). ggplot2: Elegant graphics for data analysis, Springer-Verlag New York. https://ggplot2.tidy verse.org

Wickham, H., François, R., Henry, L. and Müller, K. (2018). Dplyr: A grammar of data manipulation. $\mathrm{R}$ package version 0.8.3 ed., https://CRAN.R-project.org/package=dplyr

Received for review, March 24, 2020 Revised, July 27, 2020 Accepted, September 4, 2020 